\title{
Effects of dietary sodium on blood pressure in IDDM patients with nephropathy
}

\author{
I. Mühlhauser ${ }^{1}$, K. Prange ${ }^{1}$, P.T. Sawicki ${ }^{1}$, R. Bender ${ }^{1}$, A. Dworschak ${ }^{2}$, W. Schaden ${ }^{2}$, M. Berger ${ }^{1}$ \\ ${ }^{1}$ Department of Metabolic Diseases and Nutrition (WHO-Collaborating Centre for Diabetes), Heinrich-Heine University of \\ Düsseldorf, Germany \\ ${ }^{2}$ Nuclear Research Centre Jülich, Heinrich-Heine University of Düsseldorf, Germany
}

Summary The objectives of the study were to assess the effects of moderate sodium restriction on blood pressure in insulin-dependent diabetic (IDDM) patients with nephropathy and high normal or mildly hypertensive blood pressure (primary objective), and to document possible associated changes of exchangeable body sodium, body volumes, components of the renin-angiotensin-aldosterone system, atrial natriuretic peptide, and catecholamines (secondary objective). Sixteen patients with untreated systolic blood pressure $\geq 140<160 \mathrm{mmHg}$ and/or diastolic blood pressure $\geq 85<100 \mathrm{mmHg}$ were included in a double-blind, randomized, placebo-controlled trial. After a 4-week run-in period on their usual diet and a 2-week dietary training period to reduce sodium intake to about $90 \mathrm{mmol} / \mathrm{day}$, eight patients received $100 \mathrm{mmol} /$ day sodium supplement (group 2) and eight patients a matching placebo (group 1) for 4 weeks while continuing on the reduced-sodium diet. Patients were examined at weekly intervals. Main response variables were mean values of supine and sitting systolic and diastolic blood pressure as measured in the clinic and by the patients at home. The differences in blood pressure between the beginning and the end of the blinded 4-week study period were calculated and the differences in changes between the two patient groups were regarded as the main outcome parameters. During the blinded 4-week study period, average urinary so- dium excretion was $92 \pm 33$ (mean \pm SD) $\mathrm{mmol} /$ day in group 1 and $199 \pm 52 \mathrm{mmol} /$ day in group 2 $(p=0.0002)$. The differences in blood pressure changes between the two patient groups were 3.9(-1.2 to 9) $\mathrm{mmHg}$ [mean (95\% confidence intervals)] for systolic home blood pressure, $0.9(-3.7$ to 5.5$) \mathrm{mmHg}$ for diastolic home blood pressure, $4.9(-3.3$ to 13.1$)$ $\mathrm{mmHg}$ for clinic systolic blood pressure and 5.3(1 to $9.7 \mathrm{mmHg}, p=0.02$ ) for clinic diastolic blood pressure. Combining all patients, there were relevant associations between changes of urinary sodium excretion and blood volume (Spearman correlation coefficient $r=0.57$ ), blood pressure and angiotensin II (diastolic: $r=-0.7$; systolic: $r=-0.48$ ), and exchangeable body sodium and renin activity $(r=-0.5)$. In conclusion, in this study of IDDM patients with nephropathy and high normal or mildly hypertensive blood pressure, a difference in sodium intake of about $100 \mathrm{mmol} /$ day for a period of 4 weeks led to a slight reduction of clinic diastolic blood pressure. Studies including larger numbers of patients with various stages of nephropathy and hypertension are needed to definitely clarify the effects of sodium restriction in IDDM. [Diabetologia (1996) 39: 212-219]

Key words Dietary sodium, diabetes mellitus, blood pressure, nephropathy, body volumes, exchangeable body sodium, renin-angiotensin-aldosterone system, atrial natriuretic peptide, noradrenaline.
Received: 14 February 1995 and in final revised form 13 July 1995

Corresponding author: Priv.-Doz. Dr. med. I. Mühlhauser, Medizinische Klinik der Universität Düsseldorf, Klinik für Stoffwechselkrankheiten und Ernährung, Moorenstrasse 5, D-40225 Düsseldorf, Germany
Abbreviations: ACE, Angiotensin converting enzyme; ANP, atrial natriuretic peptide; $C V$, coefficient of variation; GFR, glomerular filtration rate; RPF, renal plasma flow; PAH, paraaminohippuric acid. 
Sodium retention is a prominent feature of insulindependent (IDDM) and non-insulin-dependent (NIDDM) diabetes and has been implicated in the pathogenesis of hypertension in these patients [1-7]. Exchangeable body sodium is increased in diabetes [1-6], and particularly high values have been found in diabetic subjects with hypertension and nephropathy $[5,6]$. In these patients levels of exchangeable body sodium were related to blood pressure values $[5,6]$. Salt sensitivity on acute sodium loading and depletion is common among patients with NIDDM and hypertension [7]. Based on these pathophysiological considerations, effects of treatment on blood pressure by reduction of dietary sodium intake could be particularly pronounced in diabetic patients with nephropathy.

Restriction of dietary sodium to less than $100 \mathrm{mmol}$ per day is generally recommended to nondiabetic and diabetic patients with hypertension [8]. However, in non-diabetic subjects effects on blood pressure may be modest in the young and lean with only mild hypertension [9]. Only few studies have been published on the effects of sodium restriction in diabetes. In one study, including elderly and overweight NDDM patients a reduction of sodium intake by $80 \mathrm{mmol}$ per day resulted in a decrease of $10 \mathrm{mmHg}$ of supine systolic blood pressure [10]. No studies have been performed in hypertensive IDDM patients. Typically, these patients are young and nonobese, and in most cases, hypertension is associated with diabetic nephropathy.

In patients with IDDM and nephropathy early and aggressive antihypertensive treatment impressively improves morbidity and mortality [11-13]. It is recommended that early increases of blood pressure, even below diastolic values of $90 \mathrm{mmHg}$, should be treated $[14,15]$. In such patients non-pharmacological antihypertensive interventions are particularly encouraged [16]. We have previously reported that IDDM patients with hypertension have shown interest in trying non-pharmacological means of lowering blood pressure [17]. However, compliance with a sodium-restricted diet was poor, even in well-trained patients using home blood pressure monitoring $[17$,
18]. This could be due to a lack of effect of this treatment or to patients' perceived restrictions in lifestyle imposed by the diet.

Thus, the present study was performed in order to investigate whether sodium restriction has clinically meaningful effects on blood pressure in IDDM patients with nephropathy and high normal or mildly hypertensive blood pressure values, and to document possible associated changes of exchangeable body sodium and components of related regulatory systems.

\section{Subjects and methods}

Study hypothesis and a priori sample size calculations. The study hypothesis was that sodium restriction to about $90 \mathrm{mmol} / \mathrm{day}$ would lead to a reduction in blood pressure by at least $6 \mathrm{mmHg}$ when compared to a daily sodium intake of about $190 \mathrm{mmol} / \mathrm{day}$, which corresponds to the average urinary sodium excretion per $24 \mathrm{~h}$ of hypertensive IDDM patients attending the Düsseldorf diabetes centre $[17,18]$. Based upon previous studies documenting the effects of antihypertensive treatment on the prognosis of IDDM patients [11, 12] a difference of at least $6 \mathrm{mmHg}$ between groups after a study period of 4 weeks was considered to be clinically important. Applying standard formula for unpaired Student's $t$-test and assuming a standard deviation of $4 \mathrm{mmHg}$ for mean clinic blood pressure at baseline (Table 1), the required sample size was calculated as 16 patients in order to detect a difference of $6 \mathrm{mmHg}$ as statistically significant ( $\alpha=0.05$, two-tailed) with a statistical power of $80 \%$ [19].

Subjects. Over a period of 4 years, out of several hundred IDDM patients attending the University Hospital of Duisseldorf and two hospitals in the city of Essen, where identical treatment approaches for intensified insulin therapy were used [20], a total of 63 possibly suitable patients were screened in order to recruit 16 subjects who fulfilled the inclusion criteria and were willing to participate in the study (two subjects had dropped out during the unblinded dietary training period, one because he felt unable to adhere to the study protocol, the second because he felt unable to adhere to the sodium restricted diet). Inclusion criteria were: IDDM on intensified insulin therapy [20], age 18 to 60 years, diabetes duration more than 5 years, increased proteinuria ( $>60 \mathrm{mg} / 24 \mathrm{~h}$ in at least two of three 24-h urine samples), exclusion of urinary tract infection, no drugs (including oral contraceptives) except insulin (one patient used thyroxine), stable retinopathy, exclusion of pregnancy and effective contraception during the

Table 1. Clinic and home blood pressure during study periods

\begin{tabular}{|c|c|c|c|c|c|c|}
\hline & \multicolumn{2}{|c|}{ Run-in period (exam. 4-5) } & \multicolumn{2}{|c|}{ Dietary training (exam. 6-8) } & \multicolumn{2}{|c|}{ Blinded study period (exam. 9-12) } \\
\hline & Group 1 & Group 2 & Group 1 & Group 2 & Group 1 & Group 2 \\
\hline \multicolumn{7}{|c|}{ Clinic blood pressure $(\mathrm{mm} \mathrm{Hg})$} \\
\hline Systolic & $134 \pm 9$ & $139 \pm 7$ & $130 \pm 7$ & $134 \pm 7$ & $128 \pm 8$ & $135 \pm 8$ \\
\hline Diastolic & $87 \pm 4$ & $88 \pm 4$ & $86 \pm 6$ & $86 \pm 6$ & $84 \pm 4$ & $85 \pm 6$ \\
\hline Mean & $103 \pm 4$ & $105 \pm 3$ & $100 \pm 5$ & $102 \pm 6$ & $98 \pm 5$ & $101 \pm 7$ \\
\hline \multicolumn{7}{|c|}{ Home blood pressure ( $\mathrm{mm} \mathrm{Hg}$ ) } \\
\hline Systolic & $134 \pm 11$ & $139 \pm 8$ & $130 \pm 11$ & $135 \pm 8$ & $127 \pm 10$ & $136 \pm 9$ \\
\hline Diastolic & $84 \pm 6$ & $86 \pm 3$ & $83 \pm 6$ & $83 \pm 3$ & $82 \pm 4$ & $83 \pm 5$ \\
\hline Mean & $101 \pm 7$ & $104 \pm 3$ & $99 \pm 7$ & $100 \pm 3$ & $97 \pm 5$ & $100 \pm 5$ \\
\hline
\end{tabular}

Values are means \pm SD of all measurements. Exam., Examination. ${ }^{\text {a }}$ for home blood pressure examinations $3-5$ 
study; untreated systolic blood pressure $\geq 140<160 \mathrm{mmHg}$ and/or diastolic blood pressure $\geq 85<100 \mathrm{mmHg}$. A history of short-term treatment with antihypertensive drugs was not an exclusion criteria, if the medication had been stopped for at least 4 weeks before recruitment.

Study protocol. The study was designed as a double-blind, randomized, placebo-controlled trial with a simple two-group parallel design. After a 4-week run-in period on their usual diet and a 2 -week dietary training period to reduce sodium intake to about $90 \mathrm{mmol} /$ day, eight patients were randomized to receive $100 \mathrm{mmol} /$ day sodium supplement (group 2) and eight patients to matching placebo (group 1) while continuing on the reduced-sodium diet. Patients were examined at weekly intervals with five examinations during the run-in period (examination 1 to 5), three examinations during the dietary training period (examinations 6 to 8 ) and four during the blinded study period (examinations 9 to 12). Only patients who sufficiently reduced salt intake during the dietary training period were considered eligible for entering the blinded study period. The sodium supplement consisted of six coated tablets per day each containing $1 \mathrm{~g}$ of salt whereas placebo consisted of six identically coated tablets per day each containing $1 \mathrm{~g}$ of lactose. The coated tablets were kindly provided by Cassella Riedel (Frankfurt, Germany). Vials with three different numbers of tablets were provided. Vials were exchanged at each examination, and patient compliance was estimated by counting the number of returned pills. All relevant laboratory results of the blinded study period, including excretion of urinary electrolytes, were kept blinded to patients and investigators until the last patient had finished the study. Written informed consent was obtained from all subjects and the study was approved by the ethical committee of the University Hospital of Düsseldorf.

Weekly examinations were performed at the Düsseldorf diabetes clinic by a single, specially trained, non-physician investigator (K.P.). Patients were asked to always come at the same time of the day, to avoid strenuous exercise during the 24-h urine collection and to abstain from smoking before and during the examinations. Blood glucose levels were measured before and during examinations and kept within approximately 4.4 and $11 \mathrm{mmol} / \mathrm{l}$.

Blood pressure measurements. Clinic blood pressure was measured under standardized conditions using a random zero sphygmomanometer (Hawksley, Lancing, UK) as previously described [17,18]. At examinations 1 to 3 , for screening, two supine and two sitting blood pressure measurements were taken and the mean of the four measurements was used for analysis. Thereafter (examinations 4 to 12), blood pressure was measured as follows: after the patient had a 10 -min rest in the supine position, four supine measurements were taken at 5 min intervals. After an additional 5 min of rest in the sitting position, four sitting measurements were taken at 5-min intervals. The mean of the eight measurements was calculated and used in the analysis. Pulse rate was measured at the end of the supine period.

All patients were trained in self-monitoring of blood pressure as described [17] and provided with anaeroid manometers to be used throughout the study. At each examination patients' performance in blood pressure self-monitoring was evaluated in order that their blood pressure readings were within $2 \mathrm{mmHg}$ of the readings done by the investigator. For the purpose of this study, patients were asked to monitor blood pressure under standardized conditions on one day every week and to take two measurements at each of the following time points: in the morning, before getting up while in the supine position, at noon and in the evening (before meals) in the sitting position, and at bedtime, before going to sleep, in the supine position. The mean of the eight measurements was calculated and used in the analysis.

Dietary intervention. All patients, together with their spouses or partners, underwent intensive dietary training by a nutritionist and a dietitian during the 2-week dietary training period. Patients were provided with specially prepared bread with reduced salt content. Dietary advice was reinforced by personal and telephone contact throughout the study. Patients were asked to keep their body weight constant. At the end of the run-in period, at the end of the dietary training period and at the end of the 4-week blinded study period, patients completed a 3-day food diary as described elsewhere [21]. During the last day of these 3 days, patients collected a 24 -h urine sample. Salt intake and protein intake were estimated by analysis of the dietary protocol and analysis of the urine; protein intake was calculated from 24-h urinary nitrogen excretion [18].

Laboratory methods. Metabolic investigations were carried out at the beginning (examination 8) and at the end (examination 12) of the double blind study period under standardized conditions at the same time of the day (afternoon). Blood was taken after patients had been recumbant for $1 \mathrm{~h}$ [aldosterone, angiotensin converting enzyme (ACE), atrial natriuretic peptide (ANP), adrenaline, noradrenaline] and $2 \mathrm{~h}$ (renin, renin activity, angiotensin II), respectively. Blood samples were put on ice immediately, centrifuged at $4{ }^{\circ} \mathrm{C}$, and stored at $-20^{\circ}$ and $-70^{\circ}$, respectively, for later determination. Plasma concentrations of components of the renin-angiotensin-aldosterone system and catecholamines were assayed in the laboratory of Professor Dr. med. B. Grabensee (Department of Nephrology, University Düsseldorf) using previously described methods $[22,23]$. Aldosterone (intraassay coefficient of variation, $\mathrm{CV}$ $3.4 \%$ ), renin activity (CV 5.6\%), ANP (CV 4.4\%), and ACE (CV $4.8 \%$ ) were determined by radioimmunoassay, and adrenaline (CV $3.5 \%$ ) and noradrenaline (CV $3.1 \%$ ) by highpressure liquid chromatography. Plasma angiotensin II levels (CV 5.5\%) were assayed in the laboratory of Professor Dr. med. E. Hackenthal (Institute of Pharmacology, University of Heidelberg, Germany) [24]. Glomerular filtration rate (GFR) was assessed by the clearance of inulin and renal plasma flow (RPF) by the clearance of PAH (para-aminohippuric acid); both measurements were performed at the time of examinations 8 and 12 [25]. Renal vascular resistance was estimated by dividing [mean arterial blood pressure $\times 100 \times(1$-haematocrit)] by RPF and is expressed as $\mathrm{mmHg} \cdot \mathrm{L}^{-1} \cdot \mathrm{s}^{-1}$. Filtration fraction was calculated by dividing GFR by RPF. Total exchangeable body sodium, blood volume, plasma volume and erythrocyte volume were determined at examinations 8 and 12 at the Nuclear Research Centre, Jülich, Germany. Total exchangeable sodium was measured by the whole body counter method [26] in three patients, and by a modified isotope dilution method [27] in 13 patients using $\mathrm{Na}-22$. Blood volume, erythrocyte volume, and plasma volume were measured using Tc-99 m labelled erythrocytes [28].

\section{Statistical analysis}

The main response variables were the mean values of the supine and sitting blood pressure measurements as assessed at the clinic and by the patients at home. The differences in blood pressure between the beginning (examination 8) and the end (examination 12) of the blinded 4-week study period were calculated and the differences in changes of blood pres- 
Table 2. Dietary parameters according to dietary protocols, analyses of urine, and metabolic data

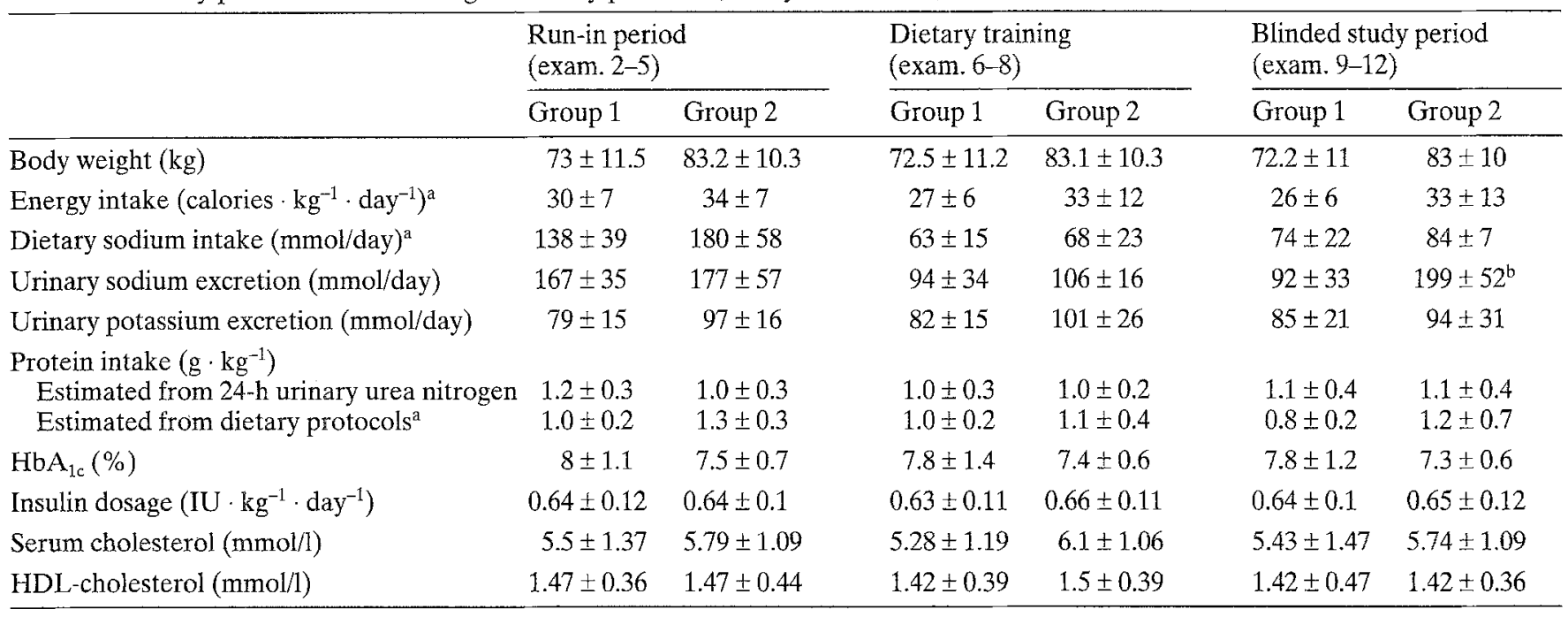

Values are means \pm SD of all measurements during the three trial periods. Exam., Examination

${ }^{a}$ According to 3-day dietary protocols assessed at the end of the respective study periods; ${ }^{b} \mathrm{p}=0.0002$ ( $\mathrm{t}$-test) compared to group 1

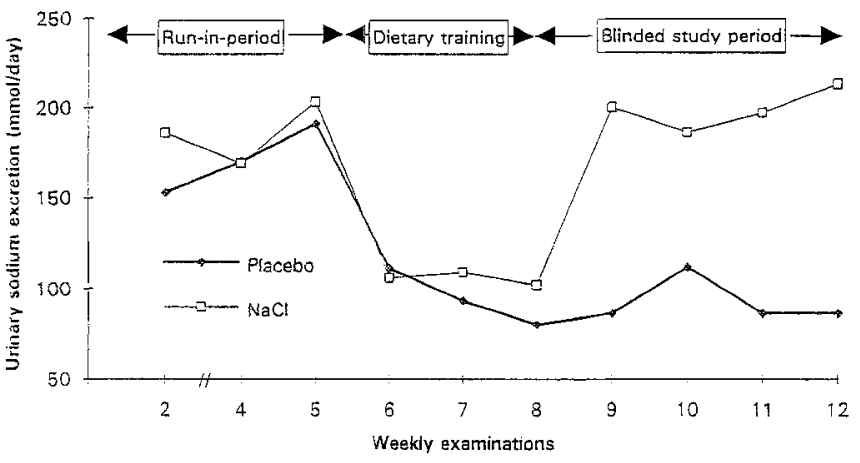

Fig. 1. Sodium excretion during the run-in-period, the dietary training period and the blinded study period. Values are means

sure between the two patient groups were regarded as the main outcome parameters. In an additional analysis, differences in blood pressure between groups at examination 12 were assessed. Means, standard deviations and $95 \%$ confidence intervals were calculated using standard formulas. Differences between groups were assessed by the Student's t-test and - for blood pressure measurements - by analysis of covariance to adjust for baseline values. Two-tailed $p$-values for $t$-tests were calculated without and with adjustment for multiple comparisons using the Sidák inequality and bootstrapping [29]. For computations the SAS procedures MEANS, TTEST [30] and MULTTEST were used [31]. Associations between changes (from examinations 8 to 12) of clinic blood pressure, urinary sodium excretion, exchangeable body sodium, body volumes, components of related regulatory systems, and renal parameters were assessed by Spearman's rank correlation coefficient.

\section{Results}

Patients in group 1 (three women, five men) and group 2 (one woman, seven men) were comparable with respect to age ( $35 \pm 11$ vs $37 \pm 9$ years), diabetes duration ( $23 \pm 5$ vs $22 \pm 10$ years), body mass index $\left(24.9 \pm 3\right.$ vs $\left.25.2 \pm 3.1 \mathrm{~kg} / \mathrm{m}^{2}\right), \quad \mathrm{HbA}_{1 \mathrm{c}}(8 \pm 1$ vs $7.5 \pm 0.7 \%$; reference range $4.3-6.1 \%)$, insulin dosage $\left(0.64 \pm 0.14\right.$ vs $0.65 \pm 0.09 \mathrm{IU} \cdot \mathrm{kg}^{-1} \cdot$ day $\left.^{-1}\right)$, smoking status, and status of retinopathy. One patient in each group had autonomic neuropathy on heart rate response to standing. All but two patients had been told previously that they had increased blood pressure values. Four patients from group 1 , and three patients from group 2 had been treated short-term with antihypertensive drugs. At recruitment, according to Joint National Committee criteria [16] three patients from group 1 and one patient from group 2 had high normal blood pressure, whereas the remaining patients had hypertensive blood pressure values.

The desired levels of urinary sodium excretion were achieved and maintained in both patient groups throughout the study (Fig. 1, Table 2). Patient compliance to dietary recommendations was high according to both urinary excretion of electrolytes and dietary protocols (Table 2). There were no significant changes in body weight, protein intake, urinary excretion of potassium (Table 2), calcium, phosphate, urea nitrogen; no changes in serum levels of electrolytes, urea nitrogen, uric acid, creatinine, albumin, protein (data not shown), and no changes of parameters related to diabetes control, such as $\mathrm{HbA}_{1 \mathrm{c}}$-levels, insulin dosage or blood lipids (Table 2). Patient compliance to drug intake was high according to the estimated proportion of consumed tablets [group 1: 98 (range 94-103)\%; group 2: 99 (96-102)\%].

Results for blood pressure changes are shown in Tables 1 and 3 . There were no statistically significant changes in blood pressure except for the difference between groups in changes of clinic diastolic blood pressure between examinations 8 and 12 (Table 3 ). Results did not change after adjustment for baseline values (ANCOVA). In addition, blood pressure val- 
Table 3. Blood pressure measurements

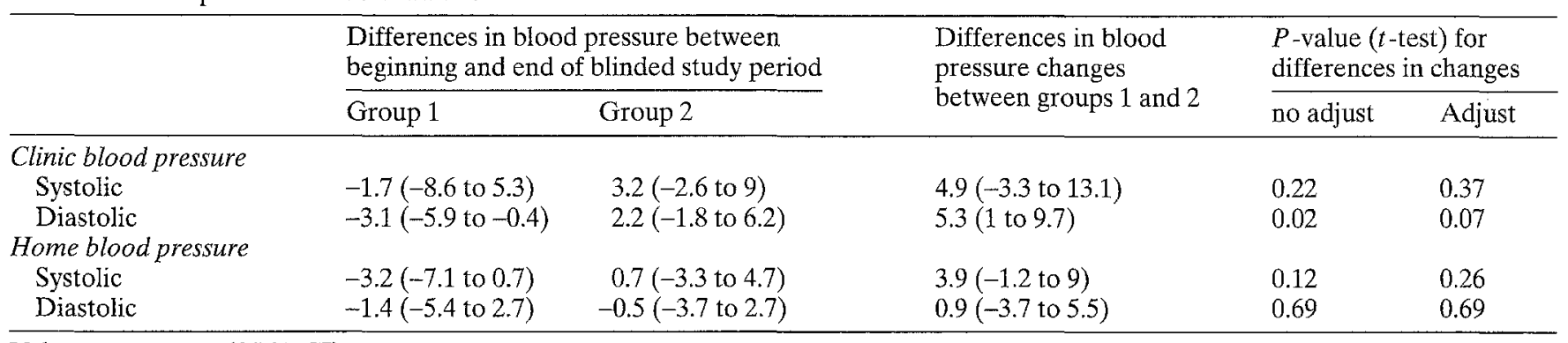

Values are means ( $95 \%$ CI)

Adjust, Adjustment for multiple comparison

Table 4. Renal parameters at beginning and end of the blinded study period

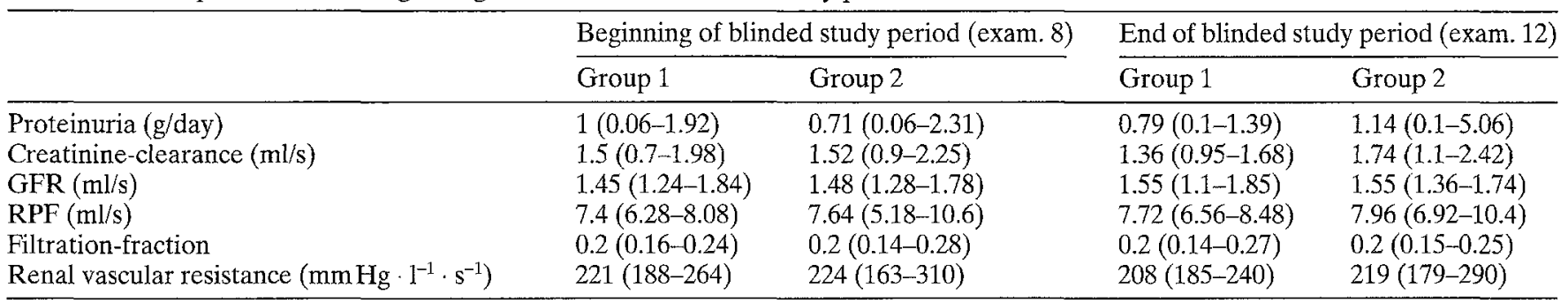

Values are means (range). Exam., Examination

Table 5. Plasma concentrations of components of the renin-angiotensin-aldosterone system, atrial natriuretic peptide, and catecholamines

\begin{tabular}{|c|c|c|c|c|}
\hline & \multicolumn{2}{|c|}{ Beginning of blinded study period (exam. 8) } & \multicolumn{2}{|c|}{ End of blinded study period (exam. 12) } \\
\hline & Group 1 & Group 2 & Group 1 & Group 2 \\
\hline Aldosterone $(\mathrm{pmol} / \mathrm{l})$ & $330(240-490)$ & $230(100-340)$ & $310(90-870)$ & $200(120-390)$ \\
\hline Renin activity (ng $\cdot \mathrm{l}^{-1} \cdot \mathrm{s}^{-1}$ ) & $1.7(0.64-4.34)$ & $1.98(0.44-8.02)$ & $1.16(0.44-2.22)$ & $1.2(0.42-4.28)$ \\
\hline Angiotensin converting enzyme (U/1) & $89(65-116)$ & $82(46-118)$ & $85(47-105)$ & $85(71-108)$ \\
\hline Angiotensin II $(\mathrm{pg} / \mathrm{ml})$ & $62(17-227)$ & $79(12-164)$ & $45(15-102)$ & $61(12-248)$ \\
\hline Noradrenaline (nmol/l) & $1.42(0.71-1.29)$ & $1.04(0.4-2.49)$ & $0.9(0.65-1.39)$ & $0.98(0.61-1.66)$ \\
\hline
\end{tabular}

Values are means (range). Exam., Examination

ues at the end of the study (examination 12) were not significantly different between groups after adjustment for baseline values (clinic systolic: $p=0.16$, clinic diastolic: $p=0.27$, home systolic: $p=0.057$, home diastolic: $p=0.88$ ). Pulse rate did not change between examinations 8 and 12 (group 1: $86 \pm 9$ vs $85 \pm 6$ beats $/ \mathrm{min}$; group $2: 85 \pm 5$ vs $87 \pm 5$ beats $/ \mathrm{min}$ ).

There were no significant group effects with respect to changes of renal parameters (Table 4), the various components of the renin-angiotensin-aldosterone system, ANP, adrenaline or noradrenaline (Table 5), exchangeable body sodium and body volumes (Table 6).

Combining all patients, there were relevant associations (Spearman correlation coefficient $r \geq 0.3$ ) between changes from the beginning to the end of the blinded study period (examinations 12-8) for various parameters: changes of urinary sodium excretion were related to changes of blood volume $(r=0.57)$, erythrocyte volume $(r=0.4)$ and plasma volume $(r=0.38)$; changes of clinic diastolic blood pressure were related to changes of renin activity $(r=0.3)$, angiotensin II $(r=-0.7)$, ACE $(r=0.41)$ and noradrenaline $(r=0.39)$; changes of clinic systolic blood pressure were related to changes of erythrocyte volume $(r=-0.32)$, angiotensin II $(r=-0.48)$, ACE $(r=0.39)$ and adrenaline $(r=0.46)$; changes of exchangeable body sodium were related to changes of blood volume $(r=0.39)$, erythrocyte volume $(r=0.46)$, renin activity $(r=-0.5)$, ACE $(r=0.33)$ and noradrenaline $(r=0.31)$.

\section{Discussion}

This is the first report on treatment effects of sodium restriction in IDDM patients with nephropathy and untreated high normal or mildly hypertensive blood 
Table 6. Exchangeable body sodium and body volumes at beginning and end of the blinded study period

\begin{tabular}{|c|c|c|c|c|}
\hline & \multicolumn{2}{|c|}{ Beginning of blinded study period (exam. 8) } & \multicolumn{2}{|c|}{ End of blinded study period (exam. 12) } \\
\hline & Group 1 & Group 2 & Group 1 & Group 2 \\
\hline Exchangeable sodium (mmol/kg) & $41.5 \pm 5.1$ & $42.7 \pm 4.4$ & $41.7 \pm 5.2$ & $44.8 \pm 7.3$ \\
\hline Erythrocyte volume (ml/kg) & $25.6 \pm 4.8$ & $24.9 \pm 3.2$ & $23.4 \pm 3.7$ & $24.6 \pm 2.8$ \\
\hline Plasma volume $(\mathrm{ml} / \mathrm{kg})$ & $39.8 \pm 8.8$ & $42.4 \pm 9.5$ & $39.3 \pm 7.7$ & $43.2 \pm 6.2$ \\
\hline Haematocrit & $0.42 \pm 0.03$ & $0.41 \pm 0.03$ & $0.41 \pm 0.03$ & $0.4 \pm 0.03$ \\
\hline
\end{tabular}

Values are means \pm SD. Exam., Examination

pressure values. In this particular study population, a 4-week restriction of dietary sodium to the recommended daily intake of about 90 mmol per day compared to the normal sodium consumption of our IDDM patients of about $190 \mathrm{mmol}$ per day did not lead to significant reductions in home blood pressure and systolic clinic blood pressure, whereas clinic diastolic blood pressure decreased by about $5 \mathrm{mmHg}$.

Patient compliance to the dietary regimen and intake of the salt-/placebo tablets was high as estimated by analysis of dietary protocols, excretion of urinary electrolytes and on pill counting at weekly intervals. Thus, a sufficient difference in sodium intake between the two patient groups was achieved and maintained throughout the 4-week blinded study period. It is of note that previously studied populations of diabetic patients had lower urinary sodium excretion rates $[1,2,4-6]$ than the patients attending the diabetes centre of the University hospital of Düsseldorf $[17,18]$. Consequently, the effects of reducing sodium intake to about $90 \mathrm{mmol}$ per day on lowering blood pressure are expected to be even less pronounced in other groups of diabetic patients with lower levels of sodium intake at baseline.

Various factors could have influenced the results of the present study. First, according to the blood pressure values at the end of the blinded trial period, the power of the study was not sufficiently high to justify the conclusion that sodium restriction does not lower blood pressure in patients with IDDM and nephropathy. Second, differences in blood pressure between the two treatment groups might be missed on clinic and home blood pressure monitoring as performed in the present investigation. In fact, ambulatory 24-h blood pressure monitoring was not included as an assessment method at the time the study was being planned and initiated. Ambulatory 24-h blood pressure monitoring may be necessary in order to identify treatment effects on night-time blood pressure, especially in patients whose blood pressure does not fall during sleeping hours. However, marked reductions in fall of nocturnal blood pressure have only been observed in patients with advanced diabetic nephropathy receiving antihypertensive therapy and in some patients with pronounced autonomic neuropathy, whereas IDDM patients with microalbuminuria or overt nephropathy with no antihypertensive medication still had normal or only slightly disturbed diurnal blood pressure variation [32-34]. Third, the study period could have been too short. The effects of sodium restriction usually manifest themselves within a few days or weeks, although further effects may become apparant only on longterm treatment. On the other hand, patients usually become less compliant with longer study periods, counterbalancing possible further treatment effects. Finally, on the basis of the present study, it cannot be excluded that dietary sodium restriction to $90 \mathrm{mmol}$ per day has relevant effects on blood pressure in patients with an even higher daily sodium intake than that of the patients in this study, in patients with more advanced diabetic nephropathy, in patients with moderate to severe hypertension, in patients already treated with antihypertensive agents or in older patients with IDDM.

In the present study, sodium restriction had no group effects on exchangeable body sodium, blood volume, erythrocyte volume, plasma volume, the renin-angiotensin-aldosterone system, atrial natriuretic peptide or catecholamines. However, the study did not have the statistical power to detect minor, though real differences between the two patient groups. In addition, the patients of the present study were homogeneous with respect to age, body mass index, insulin therapy and metabolic control, and due to the inclusion criteria they displayed a narrow range of blood pressure values. Associations between sodium intake and blood pressure and exchangeable body sodium, respectively, have been observed in patient groups with wide ranges of clinical characteristics and of blood pressure values [1-7]. Furthermore, it cannot be excluded that transient and significant changes, e.g. in the renin-angiotensin-system had occurred within the first days of alterations in sodium intake and that these changes had been missed by our study protocol. Likewise, it might take more than 4 weeks to significantly alter total exchangeable body sodium.

On the other hand, when both patient groups of the present study were combined, relevant associations were found between changes from the beginning to the end of the blinded study period for vari- 
ous parameters. Due to small patient numbers and the large number of variables the correlation analysis was performed only in a descriptive way. In the present study, changes in urinary sodium excretion were correlated $(r \geq 0.3)$ with changes in blood volume, erythrocyte volume and plasma volume, and changes in exchangeable body sodium were related to changes in blood volume, erythrocyte volume, ACE and noradrenaline, whereas exchangeable body sodium was inversely related to renin activity. Changes in blood pressure were related to renin activity, ACE and noradrenaline, and inversely related to angiotensin II. Associations between exchangeable body sodium and blood or plasma volume have been described by some [35], but not by all authors $[1-3,6]$. High renin activity and/or increased sympathetic activity on low sodium diets have been described in non-diabetic subjects $[9,36,37]$, and high renin activity has also been found in NIDDM subjects on sodium reduction to $20 \mathrm{mmol} /$ day [7]. The predictive role of high plasma renin activity for an increased risk of myocardial infarction is controversial $[37,38]$. In a cross-sectional analysis including IDDM patients with various degrees of nephropathy and hypertension, Feldt-Rasmussen et al. [6] found suppressed aldosterone, angiotensin II and catecholamine levels in patients with increased blood pressure and early stages of diabetic renal disease. This is in accordance with the strong inverse relationship between changes of blood pressure and angiotensin II observed in the present study.

In conclusion, in contrast to the previously described pronounced effects of sodium restriction on blood pressure in overweight NIDDM patients, the present study does not support the concept of a strong antihypertensive effect of dietary sodium restriction in IDDM patients with nephropathy and high normal or mildly hypertensive blood pressure values.

Acknowledgements. The study has been supported by Cassella Riedel, Frankfurt, Germany, and by the P. Klöckner Stiftung, Duisburg, Germany. We thank Dr. F. Best, Katholisches Krankenhaus St. Josef, Essen, Germany, and Dr. B. SchulzeSchleppinghoff, Elisabeth Krankenhaus, Essen, Germany for their co-operation in recruiting patients for the study. We acknowledge the help of Dr. oec. troph. A. Venhaus for providing the dietary training of the patients, and for the collection and analysis of the dietary data. We thank Dr. J. Plum, Department of Nephroplogy, University Düsseldorf, for the measurement of hormone values. In addition, we acknowledge the support of Professor Dr. L. E. Feinedegen from the Kernforschungszentrum Jülich. We thank Professor H.-J. Trampisch, Institut für Medizinische Informatik und Biomathematik, Ruhr-Universität Bochum, for his assistance in the planning of the study.

\section{References}

1. de Châtel R, Weidmann P, Flammer J, Ziegler WH, Beretta-Piccoli C, Vetter W, Reubi FC (1977) Sodium, renin, aldosterone, catecholamines, and blood pressure in diabetes mellitus. Kidney Int 12: 412-421

2. Weidmann P, Beretta-Piccoli C, Trost BN (1985) Pressor factors and responsiveness in hypertension accompanying diabetes mellitus. Hypertension 7[Suppl 2]:33-42

3. Weidmann P, Ferrari P (1991) Central role of sodium in hypertension in diabetic subjects. Diabetes Care 14: 220-232

4. Trevisan R, Fioretto P, Semplicini A et al. (1990) Role of insulin and atrial natriuretic peptide in sodium retention in insulin-treated IDDM patients during isotonic volume expansion. Diabetes 39: 289-298

5. O'Hare JA, Ferriss JB, Brady D, Twomey B, O'Sullivan DJ (1985) Exchangeable sodium and renin in hypertensive diabetic patients with and without nephropathy. Hypertension 7[Suppl 2]:43-48

6. Feldt-Rasmussen B, Mathiesen ER, Deckert T, Giese J, Christensen NJ, Bent-Hansen L, Nielsen MD (1987) Central role for sodium in the pathogenesis of blood pressure changes independent of angiotensin, aldosterone and catecholamines in type 1 (insulin-dependent) diabetes mellitus. Diabetologia 30: 610-617

7. Tuck M, Corry D, Trujillo A (1990) Salt-sensitive blood pressure and exaggerated vascular reactivity in the hypertension of diabetes mellitus. Am J Med 88: 210-216

8. Diabetes and Nutrition Study Group of the European Association for the Study of Diabetes -1988 (1988) Nutritional recommendations for individuals with diabetes mellitus. Diab Nutr Metab 1: 145-149

9. Alderman MH (1994) Non-pharmacological treatment of hypertension. Lancet 344: 307-311

10. Dodson PM, Beevers M, Hallworth R, Webberley MJ, Fletcher RF, Taylor KG (1989) Sodium restriction and blood pressure in hypertensive type II diabetics: randomised blind controlled and crossover studies of moderate sodium restriction and sodium supplementation. BMJ 298: $227-230$

11. Mogensen CE (1982) Long-term antihypertensive treatment inhibiting progression of diabetic nephropathy. BMJ 285: 685-688

12. Parving HH, Andersen AR, Smidt UM, Svensen PA (1983) Early aggressive antihypertensive treatment reduces rate of decline in kidney function in diabetic nephropathy. Lancet I:1175-1179

13. Mathiesen ER, Borch-Johnsen K, Jensen DV, Deckert T (1989) Improved survival in patients with diabetic nephropathy. Diabetologia 32: 884-886

14. The Working Group on Hypertension in Diabetes (1987) Statement on hypertension in diabetes mellitus. Final report. Arch Int Med 147: 830-842

15. Krans HMJ, Porta M, Keen H (1992) Diabetes care and research in Europe, the St Vincent declaration action programme. Implementation document. Giorn Ital Diabetol 12 [Suppl 2]:22-26

16. American Diabetes Association (1993) Treatment of hypertension in diabetes. Diabetes Care 16: 1394-1401

17. Mühlhauser I, Sawicki P, Didjurgeit U, Jörgens V, Berger M (1988) Uncontrolled hypertension in type 1 diabetes: assessment of patients' desires about treatment and improvement of blood pressure control by a structured treatment and teaching programme. Diabet Med 5: 693698

18. Sawicki PT, Didjurgeit U, Mühlhauser I, Bender R, Heinemann L, Berger M (1994) Smoking is associated with 
progression of diabetic nephropathy. Diabetes Care 17: 126-131

19. Bock J, Toutenburg H (1991) Sample size determination in clinical research. In: Rao CR, Chakraborty R (eds) Handbook of statistics, vol 8. Elsevier, Amsterdam, pp 515-538

20. Jörgens V, Grüsser M, Bott U, Mühlhauser I, Berger M (1993) Effective and safe translation of intensified insulin therapy to general internal medicine departments. Diabetologia 36: 99-105

21. Venhaus A, Chantelau E (1988) Self-selected unrefined and refined carbohydrate diets do not affect metabolic control in pump-treated diabetic patients. Diabetologia 31: 153-157

22. Heering P, Kutkuhn B, Kreuzpaintner G, Reinhard T, Sundmacher R, Grabensee B (1991) Untersuchungen zur Nierenfunktion nierengesunder Patienten unter Ciclosporin. Klin Wochenschr 69: 880-886

23. Plum J, Grabensee B (1991) Atrial natriuretic peptide in dialysis patients under various conditions of volume homeostasis. J Int Med 229: 209-216

24. Oster P, Hackenthal E, Hepp R (1973) Radioimmunoassay of angiotensin II in rat plasma. Experientia 29: 353-354

25. Schnurr E, Lahme W, Küppers H (1980) Measurements of renal clearance of inulin and PAH in the steady state without urine collection. Clin Nephrol 13: 26-29

26. Kunkel R, Oberhausen E (1968) Die gleichzeitige Bestimmung des Gesamtkaliums und des austauschbaren Natriums beim Menschen. In: Hoffmann G, Höfer R (eds) Radionuklide in Kreislaufforschung und Kreislaufdiagnose. Schattauer, Stuttgart, New York, pp 411-415

27. Miller H, Wilson GM (1953) The measurement of exchangeable sodium in man using the isotope $\mathrm{Na}-24$. Clin Science 12: 97-111

28. Hermann H-J (1982) Nuklearmedizin. Urban und Schwarzenberg, München, Wien, Baltimore, pp 337-347
29. Westfall PH, Young SS (1993) Resampling-based multiple testing. Wiley, New York

30. SAS/STAT (1987) Guide for Personal Computers. Version 6 edn. SAS Institute Inc, Cary, N.C.

31. SAS Technical Report P-229 (1992) SAS/STAT Software: Changes and Enhancements, Release 6.07. SAS Institute Inc., Cary, N.C.

32. Hansen KW, Christiansen CK, Andersen PH, Pedersen MM, Christiansen JS, Mogensen CE (1992) Ambulatory blood pressure in microalbuminuric type 1 diabetic patients. Kidney Int 41: 847-854

33. Hansen KW, Pedersen MM, Marshall SM, Christiansen JS, Mogensen CE (1992) Circadian variation of blood pressure in patients with diabetic nephropathy. Diabetologia 35: 1074-1079

34. Liniger C, Favre L, Assal J-Ph (1991) Twenty-four hour blood pressure and heart rate profiles of diabetic patients with abnormal cardiovascular reflexes. Diabet Med 8: $420-427$

35. Brochner-Mortensen J (1973) Glomerular filtration rate and extracellular fluid volume during normoglycemia and moderate hyperglycemia in diabetes. Scand J Clin Lab Invest $32: 311-316$

36. MacGregor GA, Markandu ND, Sagnella GA, Singer DRJ, Cappuccio FP (1989) Double-blind study of three sodium intakes and long-term effects of sodium restriction in essential hypertension. Lancet II:1244-1247

37. Alderman MH, Madhavan S, Ooi WL, Cohen H, Sealey JE, Laragh JH (1991) Association of the renin-sodium profile with the risk of myocardial infarction in patients with hypertension. N Engl J Med 324: 1098-1104

38. Meade TW, Cooper JA, Peart WS (1993) Plasma renin activity and ischaemic heart disease. N Engl J Med 329: 616669 